\title{
Hemorrhoids
}

\author{
Caroline Sanchez, M.D. ${ }^{1}$ and Bertram T. Chinn, M.D. ${ }^{1}$
}

\begin{abstract}
Hemorrhoid disease is the most common reason patients seek evaluation by a colon and rectal surgeon. The majority of hemorrhoids can be managed nonoperatively with medical management or office-based procedures. The authors review the anatomy, pathophysiology, presentation, and management of hemorrhoids.
\end{abstract}

KEYWORDS: Hemorrhoids, bleeding, prolapse, thrombosis, ligation, medical management

Objectives: On completion of this article, the reader should be able to summarize the clinical presentation and management of symptomatic hemorrhoid disease.

Hemorrhoids are one of the most common reasons that patients seek consultation from a colon and rectal surgeon. This disease is reported to affect around 10 million Americans per year with a prevalence of $4.4 \%$. It has previously been published that Caucasians of higher socioeconomic class were afflicted with a greater frequency and was theorized to be diet related. ${ }^{1}$ However, it remains unclear if this represents limitations to the reporting of symptoms or healthcare-seeking practices. Other contributing factors include situations that increase intraabdominal pressure such as pregnancy, constipation, or prolonged straining, as well as weakening of supporting tissue as a result of aging or genetics. It is thought that clinical disease develops as a result of dilation and distension of the veins along with weakening of the supporting connective tissue.

\section{ANATOMY AND PHYSIOLOGY}

Hemorrhoids are highly vascular submucosal cushions that generally lie along the anal canal in three columnsthe left lateral, right anterior, and right posterior positions. These vascular cushions are made up of elastic connective tissue and smooth muscle, but because some do not contain muscular walls, these cushions may be considered sinusoids instead of arteries or veins. Clinically evident bleeding arises from the perisinusoidal arterioles and are therefore arterial in nature. ${ }^{2}$ Hemorrhoids play a significant physiologic role in protecting the anal sphincter muscles and augment closure of the anal canal during moments of increased abdominal pressure (e.g., coughing, sneezing) to prevent incontinence and contribute 15 to $20 \%$ of the resting anal canal pressure. $^{2}$ Increases in abdominal pressure increase the pressure in the inferior vena cava that cause these vascular cushions to engorge and prevent leakage. This tissue is also thought to help differentiate stool, liquid, and gas in the anal canal. ${ }^{2}$

The dentate line differentiates external and internal hemorrhoids. External hemorrhoids are located below the dentate line and drain via the inferior rectal veins into the pudendal vessels and then into the internal iliac vein. These vessels are covered by anoderm that is comprised of modified squamous epithelium. As a result, these tissues contain pain fibers and affect how patients present and are treated. Internal hemorrhoids lie above
${ }^{1}$ Division of Colon and Rectal Surgery, University of Medicine and Dentistry-Robert Wood Johnson Medical School, Edison, New Jersey. Address for correspondence and reprint requests: Bertram $\mathrm{T}$. Chinn, M.D., Division of Colon and Rectal Surgery, UMDNJ-Robert Wood Johnson Medical School, 3900 Park Ave., Edison, NJ 08820 (e-mail: acrsresidency@aol.com).
Anorectal Disease; Guest Editor, Gerald A. Isenberg, M.D.

Clin Colon Rectal Surg 2011;24:5-13. Copyright (C) 2011 by Thieme Medical Publishers, Inc., 333 Seventh Avenue, New York, NY 10001, USA. Tel: +1(212) 584-4662.

DOI: http://dx.doi.org/10.1055/s-0031-1272818.

ISSN 1531-0043. 
the dentate line and are covered by columnar cells that have visceral innervations. These drain via the middle rectal veins into the internal iliac vessels. Internal hemorrhoids are classified further into the degree of prolapse. First-degree hemorrhoids protrude into the anal canal, but do not prolapse out of the canal. Second-degree hemorrhoids prolapse outside of the canal, but reduce spontaneously. Third-degree hemorrhoids prolapse out of the canal and require manual reduction; fourth-degree hemorrhoids are irreducible.

\section{CLINICAL PRESENTATION}

Patients frequently complain of bleeding with or without defecation, a swelling, mild discomfort or irritation. Other symptoms may include soilage or mucous discharge, pruritis, difficulties with hygiene, and a sense of incomplete evacuation. Internal hemorrhoids are otherwise painless unless they are thrombosed, prolapsed with edema, or strangulated. ${ }^{3}$ External hemorrhoids result in pain when a thrombosis occurs and bleeding if ulceration occurs from pressure necrosis. Skin tags may form from prior acutely edematous or thrombosed external hemorrhoids.

Symptoms from hemorrhoids are similar to other diseases and the differential diagnosis should include anal fissures, rectal prolapse, abscesses and fistulas, inflammatory bowel disease, and neoplasia. The clinical history provides clues to the etiology. Pain generally indicates a process that is distal to the dentate such as a fissure or thrombosed hemorrhoid. Bleeding is nonspecific and can result from a fissure, polyps, or cancer, inflammatory bowel disease (IBD), internal hemorrhoids, or an ulcerated thrombosis. Hemorrhoid bleeding is common, but it is uncommon for patients to present with anemia. ${ }^{4}$ Pruritis and "burning" can result from discharges or difficulty with hygiene. It may also result from a chronic wound such as a fissure or fistula, condyloma, rectal prolapse, or prolapsing hemorrhoids. A mass may be related to an abscess, skin tags, neoplasia, or a thrombosed or prolapsed hemorrhoid.

Due to the wide array of pathology, a thorough examination is required and can generally be accomplished in the office with the patient in a knee-chest, prone-jackknife, or left lateral position. Inspection of the anus and perianal region will exclude a thrombosed or prolapsing hemorrhoid. Skin tags may be a clue to prior hemorrhoid disease, but may also represent fissure disease particularly if located in the anterior or posterior location. Perianal sepsis from an abscess or fistula disease should be excluded. A digital exam may identify a distal rectal mass, an intersphincteric abscess or internal hemorrhoids. An anoscopy should be performed to identify internal hemorrhoids or fissures. A rigid or flexible sigmoidoscopy may rule out the presence of rectosigmoid neoplasia, proctitis, or IBD.
It is also important to evaluate sphincter integrity particularly in those who report incontinence as the potential for altered function exists with any anorectal surgery. Appropriate clearance of the colon for neoplasia should also be performed when indicated.

\section{TREATMENT}

Treatment is often divided between nonoperative management, office procedures, and surgical management utilizing an operating room. The least-invasive approach should be considered given the physiologic importance of the hemorrhoid cushions and the potential self-limiting nature of many hemorrhoid symptoms. The decision on how to treat depends on many factors including the degree of symptoms, age, and other medical conditions.

\section{Nonoperative Management}

All patients should benefit from minimizing straining and avoiding constipation. Bulking of the stool facilitates this and can be accomplished by increasing dietary fiber and fluid intake. Stool softeners may also be used. Sitz baths are warm soaks that provide relief by reducing swelling and sphincter spasm. ${ }^{2}$ Topical agents utilizing astringents, analgesics, and steroids help provide relief in an acute setting, but there is no evidence showing their benefit for prevention or long-term treatment of hemorrhoid disease.

\section{ACUTE THOMBOSIS OF HEMORRHOIDS}

Pain is the primary complaint with acutely thrombosed hemorrhoids and is most often external in nature. A painful swelling suddenly appears and on examination a bluish-colored lump is noted (Fig. 1). Patients may report straining, lifting, or prolonged sitting prior to the thrombosis, but many recall no antecedent event. Treatment is aimed at controlling the pain, but because the pain is due to edema and pressure, topical agents tend not to be helpful. The pain and edema have been shown to peak at 48 hours and subside after 4 days. ${ }^{2,5}$

Our experience is that excision of the thrombosis should be performed during the first 48 to 72 hours after the onset of symptoms (Fig. 2). The thrombosis should be injected with a local anesthetic and an elliptical skin incision overlying the thrombosis is made followed by excision of the entire thrombosis. Local care with sitz baths and analgesics are then started. A simple incision should be avoided as only a portion of the thrombosis may be evacuated and ongoing or worsening pain from the incision and persistent thrombosis can occur.

An ulcerated thrombosis may occur when increasing pressure from the thrombosis results in pressure necrosis and ulceration of the skin (Fig. 3). The subsequent bleeding diminishes pain from decompression of the clot. Although the pain has significantly diminished 


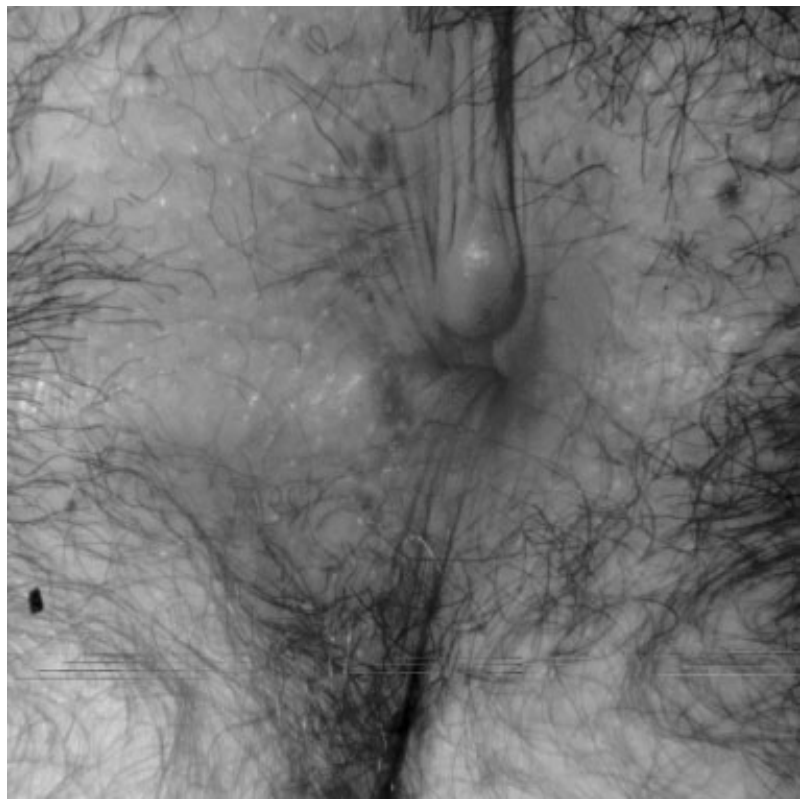

Figure 1 Hemorrhoid thrombosis.

by the time a patient presents, bleeding will usually continue until the thrombosis is excised and evacuated.

Surgical intervention for thrombosed hemorrhoids allows for a rapid resolution of symptoms. Two hundred thirty-one patients with thrombosed external hemorrhoids were divided into nonoperative and surgical management groups. ${ }^{6}$ The patients treated nonoperatively required 24 days to the time of symptom resolution compared with 3.9 days in the surgically treated group, a statistically significant difference. However, because the goal of treatment for a thrombosed hemorrhoid is pain relief, in a patient who presents with

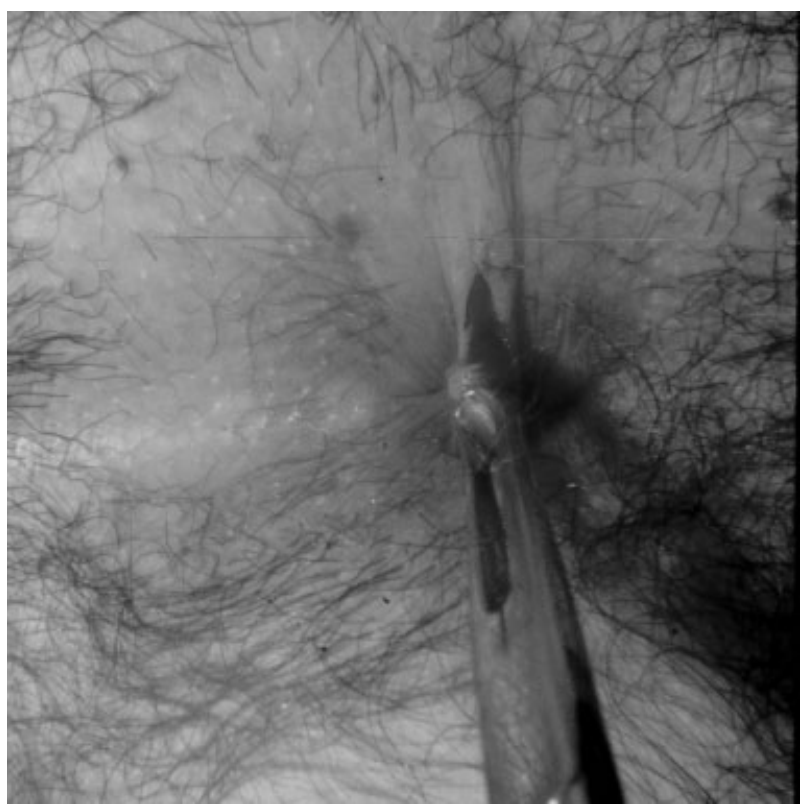

Figure 2 Excision of thrombosis.

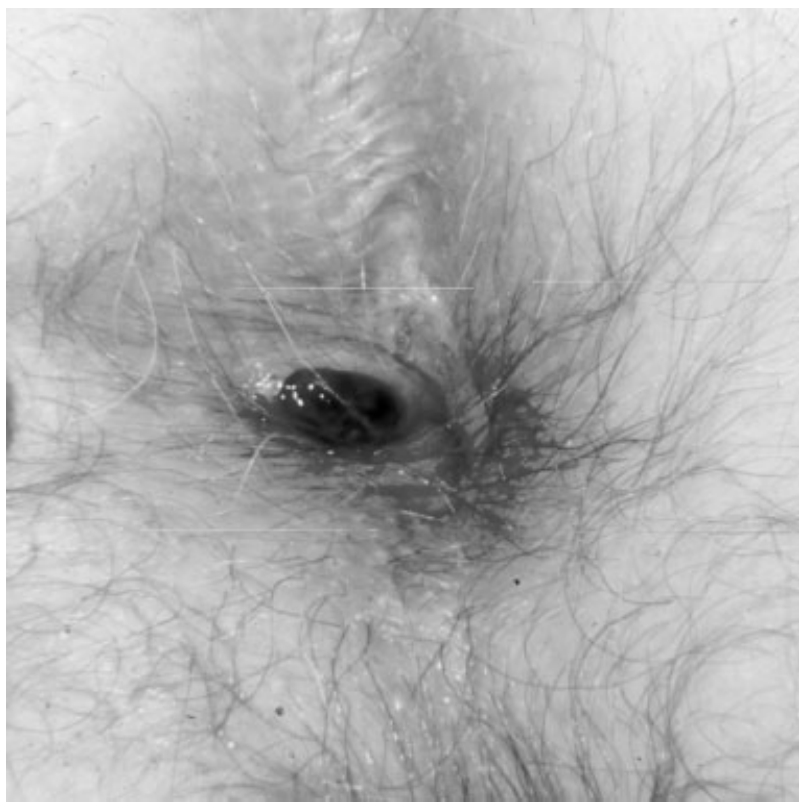

Figure 3 Ulcerated thrombosis.

improving symptoms, our recommendation is to consider analgesics and sitz baths as the pain associated with excision would exceed the pain from the resolving thrombosis.

\section{Treatment of Symptomatic Internal Hemorrhoids}

The approach to treating internal hemorrhoids depends on the degree of prolapse, symptoms, and medical history. Grade 1 and 2 internal hemorrhoids should be initially treated with dietary modifications and topical therapy using emollients, astringents, or hydrocortisone. Those who have ongoing symptoms or active bleeding should be considered for surgical treatment. These procedures include ligation, fixation, excision, or a combination of these approaches. Because most internal hemorrhoid symptoms are due to tissue prolapse, ligation and fixation procedures effectively scar the mucosa to the underlying sphincter so tissue can no longer prolapse.

\section{RUBBER BAND LIGATION}

Rubber band ligation is perhaps the most common office procedure performed as it can be accomplished quickly without anesthesia or a bowel preparation. It is most effective on first- and second-degree internal hemorrhoids and many third-degree hemorrhoids. It is successful in roughly $80 \%$ of patients, but may recur with time. $^{7-10}$ Recurrent symptoms often resolve with repeated banding and only $10 \%$ will go on to surgical excision. ${ }^{9}$

Hemorrhoid ligations are accomplished through an anoscope by grasping the hemorrhoid and redundant 
mucosa with a ligator above the dentate line. If pain is encountered, the ligation should not be performed at that site and regrasping more proximally should be performed to ensure it is insensate. The band should then be applied to the base of the tissue away from the dentate line. Over the next week the tissue distal to the ligation becomes ischemic and sloughs off. The result is tissue reduction and a scar that fixes the remaining tissue in place.

The advantage of ligations is that it can be performed in an office setting with patients resuming normal activities after treatment. This is a cost-effective treatment because operating room resources are not needed and patients are able to resume work afterward. Depending upon patient tolerance, multiple groups may be treated simultaneously, but the least amount of discomfort is achieved when groups are treated individually.

Poon et al evaluated banding single versus multiple grade 1 and 2 hemorrhoids at one setting. They found that the incidence of complications and pain were similar in both groups. ${ }^{11}$ Another study found that banding multiple groups simultaneously resulted in increased pain, increased vagal symptoms, and a higher recurrence rate. $^{12} \mathrm{~A}$ meta-analysis of 18 trials found rubber band ligation to be the most effective office procedure with a lower recurrence rate, but more overall discomfort when compared with other forms of therapy such as sclerotherapy and infrared coagulation. ${ }^{13,14}$

Complications are uncommon following ligation. In a study of 512 patients, $2 \%$ had minor pain, $1 \%$ band slippage, and $<1 \%$ developed urinary retention. However, $2.5 \%$ had complications requiring hospitalization-6 patients had massive rectal bleeding, 3 with severe pain from prolapsed thrombosed hemorrhoids and 3 with urinary retention, pain, and fever. ${ }^{8}$

Our experience is similar as most patients will experience minor pain or a dull ache for up to 48 hours that can be relieved with mild analgesics and sitz baths. Minor bleeding or spotting of blood is reported in 3 to $5 \%$ and typically occurs after 5 to 10 days from separation of the eschar. Less than $0.1 \%$ of our patients experienced bleeding requiring emergency room evaluation or hospitalization. Due to the potential for bleeding, alternative treatments should be considered for those with bleeding tendencies or on anticoagulation.

The least common but most life-threatening complication is perineal sepsis. Due to the potential for fatal outcomes, it must be considered in any patient who reports singularly or collectively increasing anal pain, fevers, or difficulty urinating/retention. These patients require evaluation to determine if the ligature requires removal. If the ligation site is gangrenous, it should also be debrided and antibiotics should be started. All patients undergoing ligation are at potential risk, but it may be greater in those who are immunocompromised, diabetic, and neutropenic.

\section{SCLEROTHERAPY}

Historically, sclerotherapy had been used in the office setting prior to ligations for internal hemorrhoid bleeding. Injection of a caustic agent into the submucosa of the hemorrhoid results in diminished vascularity, intravascular thrombosis, and fibrosis. The fibrosis is also believed to result in tissue fixation and diminish prolapse as well. In grade 1, 2, and 3 hemorrhoids, it is 75 to $89 \%$ effective, ${ }^{7,15}$ but recurrence is seen in $30 \%$ of patients at 4 years. $^{16}$

Because there is no eschar separation, postprocedure bleeding is not noted. As the patient population becomes older, more reliant on anticoagulation, and less able to tolerate complications, sclerotherapy has had a resurgence in this demographic group because it can be performed without cessation of antithrombotic therapy. Complications with sclerotherapy are rare and felt to be related to misplaced injections. Erectile dysfunction has been reported due to injection into the periprostatic parasympathetic nerves as well as life-threatening retroperitoneal sepsis. ${ }^{17,18}$

Our preference is to inject $10 \%$ phenol with cottonseed oil into the submucosa of the apex of the hemorrhoid. Approximately $1 \mathrm{~mL}$ is used or until blanching of the hemorrhoid is noted. A 21- or 25-gauge spinal needle is used to inject through the anoscope. Larger needles may result in increased bleeding. Cessation of bleeding is noted in 1 to 2 weeks and patients can be resclerosed as needed. This modality seems most effective for grade 1 and 2 hemorrhoids. It is also effective in patients with ongoing bleeding despite prior ligations when repeat ligations are not possible.

\section{Infrared Photocoagulation and Bipolar Diathermy}

Infrared photocoagulation (IRC) utilizes infrared light that is transformed into heat as it penetrates through the hemorrhoid, resulting in coagulation of cell proteins and evaporation of intracellular water. This results in sclerosis and fixation by fibrosis of the tissue and is frequently performed in an office setting. In a metaanalysis, IRC has a lower incidence of pain, but a higher recurrence rate when compared with ligation. ${ }^{7}$ Another meta-analysis found that there was less pain with IRC when compared with ligation, but IRC required more treatments to relieve symptoms. ${ }^{13}$

In IRC each hemorrhoid is coagulated 3 times for 1.5 seconds. It is recommended in the treatment of grade 1 and 2 hemorrhoids, but not for larger prolapsing hemorrhoids. As with sclerotherapy, it may be beneficial for those with ongoing symptoms despite prior ligations when repeat ligations are not possible.

Bipolar coagulation works similar to IRC by decreasing vascularity and fixes the tissue to the anal musculature. 


\section{Doppler-Guided Transanal Hemorrhoid Ligation}

Doppler guided transanal hemorrhoid artery ligation is felt to reduce the arterial inflow from the superior hemorrhoid arteries with preservation of the hemorrhoid. It uses a specially designed proctoscope with a Doppler probe and light source to identify the arteries to suture ligate. Frequently, up to six vascular pedicles are noted instead of the traditional three columns of hemorrhoids. A running suture begins at the apex of the hemorrhoid pedicle and continues down to the dentate line to ligate the internal hemorrhoid. The suture is tied back to the apex to "lift" the hemorrhoid back into its anatomic position.

Outcomes appear mixed. A study of 170 patients with grade 2,3 , and 4 disease found that $1.2 \%$ developed bleeding complications and 2.3\% developed postoperative thromboses. The recurrence rate at 1 year was $4.1 \%$, but there were no reports of fecal incontinence. ${ }^{19}$ A case series of 100 patients found a $12 \%$ recurrence rate and $6 \%$ complication rate. ${ }^{20}$ Doppler-guided hemorrhoid ligation after failed rubber band ligation identified a $23 \%$ recurrence of bleeding and or prolapse at 18 months, but reduced the need for a salvage operative hemorrhoidectomy. $^{21}$

\section{Stapled Hemorrhoidectomy}

The use of a circular stapler to treat prolapsing internal hemorrhoids involves removal of the distal rectal mucosa proximal to the hemorrhoids and dentate line. This reduces the prolapse and fixes the tissue to the rectal wall. Because the excised tissue is proximal to the somatic pain fibers in the anal canal, less postoperative pain is experienced.

A multicenter, randomized prospective trial comparing PPH (procedure for prolapse and hemorrhoids) to standard closed hemorrhoidectomy found that $\mathrm{PPH}$ was as effective and resulted in less pain and complications. ${ }^{22}$ A meta-analysis of all randomized, prospective trial comparing PPH to traditional surgery found that a $\mathrm{PPH}$ had less pain, but a greater recurrence of disease on 6-month follow-up. ${ }^{23}$

Severe complications have been reported including bleeding, incontinence, stenosis, fistula, and perineal sepsis. ${ }^{24-29}$ In women, great care should be exercised to ensure that vaginal tissue or the rectovaginal septum is not incorporated into the purse-string that may result in a rectovaginal fistula. Other rare complications include perforation, retroperitoneal sepsis, and complete rectal obstruction.

\section{Hemorrhoidectomy}

Between 5 to $10 \%$ of patients will require a formal excision or hemorrhoidectomy when they have failed or are unable to tolerate nonoperative management. ${ }^{30}$
Various approaches are described and are based on the same theory that blood flow is reduced and the excess tissue is excised. A formal excision is felt to offer the least problems with recurrent symptoms from external disease and grade 3 and 4 internal disease. The two most frequently utilized procedures are the closed Ferguson hemorrhoidectomy and the open Milligan-Morgan hemorrhoidectomy.

In the Ferguson approach, the hemorrhoid is elevated, the external skin and anoderm involved is incised. The hemorrhoid is dissected off the sphincter mechanism and excised. The pedicle is ligated and the wound closed with a running suture. In the MilliganMorgan approach, the hemorrhoid is similarly excised, but the wound is left open to epithelialize.

The two surgical approaches were compared in a prospective randomized controlled trial of patients with grade 3 and 4 disease. ${ }^{31}$ The study found that the patients who underwent the closed technique had less pain along with better wound healing; this has also been confirmed by others.

Most complaints following hemorrhoid surgery are self-limiting with the exception of an anal stenosis. Postoperative pain is expected and this may delay a return to normal activities for 3 to 4 weeks. Analgesics, the avoidance of constipation, and sitz baths are helpful in reducing pain and sphincter spasms.

Various energy sources have been used to decrease pain by attempting to decrease injury to surrounding tissues. The Harmonic Scalpel ${ }^{\circledR}$ (Ethicon Endo-Surgery, Cincinnati, $\mathrm{OH}$ ) uses ultrasound waves to cut and coagulate hemorrhoid tissue and minimize collateral thermal damage. A study comparing the Harmonic Scalpel ${ }^{\circledR}$ to traditional closed hemorrhoidectomy, however, found no difference in postoperative pain, operative time, or bleeding. ${ }^{32}$ The Ligasure ${ }^{\circledR}$ (Valleylab, Boulder, CO) utilizes bipolar diathermy and has also been used to minimize collateral tissue damage. However, the increased operative cost with these instruments along with lack of long-term results demonstrating superiority of these instruments over traditional scissor excision makes justification for their use difficult. ${ }^{33,34}$

Complications include postoperative bleeding that occurs one week after surgery and is generally due to eschar separation from the wound. Urinary retention has been reported to be as high as 34\% and is often due to pain that results in pelvic floor spasms, narcotics, anticholinergics and excessive intravenous fluids given during anesthesia. ${ }^{35,36}$ Retention can be managed with the use of a temporary Foley catheter.

Anal stenosis is generally the result of excessive resection or suturing/closure of the anoderm and is more common when multiple quadrants are excised. Stenosis can be minimized when each quadrant is excised using a 35-mm Ferguson-Hill retractor to provide exposure. The shape and size of the retractor will allow appropriate 


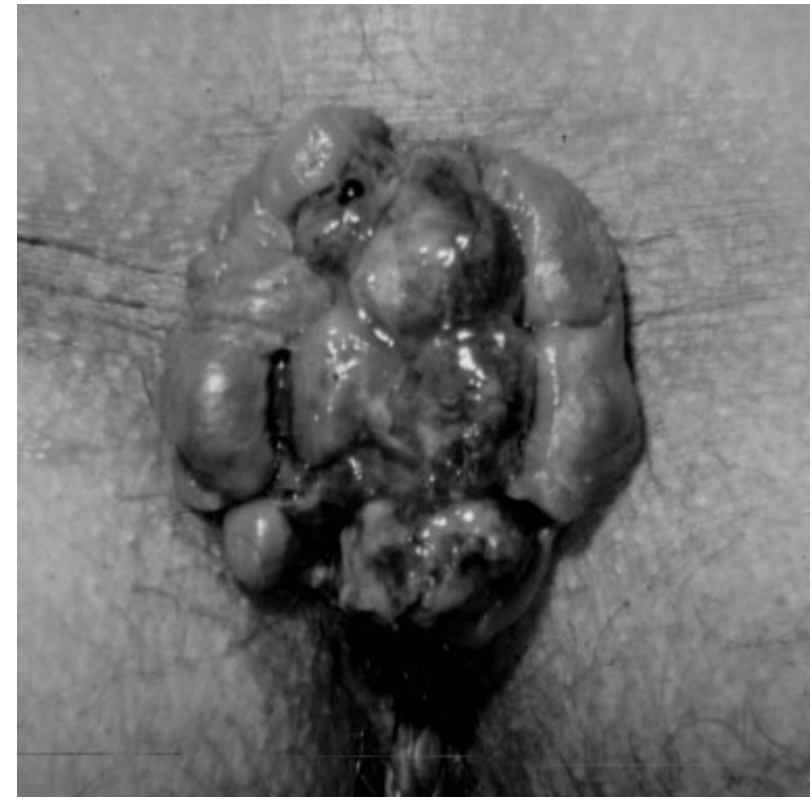

Figure 4 Acute hemorrhoid disease.

visualization of the hemorrhoid to be excised while preserving an adequate amount of anoderm behind it.

\section{THE CHALLENGING PATIENT}

\section{Acute Hemorrhoid Disease-Strangulation}

A unique presentation of prolapsed internal hemorrhoids and thrombosed external hemorrhoids require urgent intervention to prevent progression to strangulation and necrosis. Typically, all three hemorrhoid groups are involved; grade 3 hemorrhoids become incarcerated due to progressive edema from the prolapse and the external hemorrhoids become thrombosed (Fig. 4). A formal hemorrhoidectomy is performed and anesthesia is generally required due to pain.

Alternatively, if patient tolerance allows, it may be treated in the office. A local block and direct injection of the hemorrhoids with $0.25 \%$ bupivacaine with $1: 100,000$ epinephrine mixed with hyaluronidase is given (Fig. 5). Hyaluronidase catalyzes the hydrolysis of hyaluronic acid and increases tissue permeability. This enhances the dispersion of the local anesthetic and diminishes the edema and swelling of the hemorrhoid. The decrease in edema and relaxation of the sphincter from the local block allows reduction of the internal hemorrhoids. Multiple internal hemorrhoid ligations are then performed and the external thromboses are excised. This surprisingly results in a relatively normal appearing anus (Fig. 6). Due to the sphincter relaxation, the internal hemorrhoids can often be ligated without the use of an anoscope (Fig. 7). A randomized trial comparing excisions and ligations to a formal hemorrhoidectomy demonstrated both were safe and effective with a

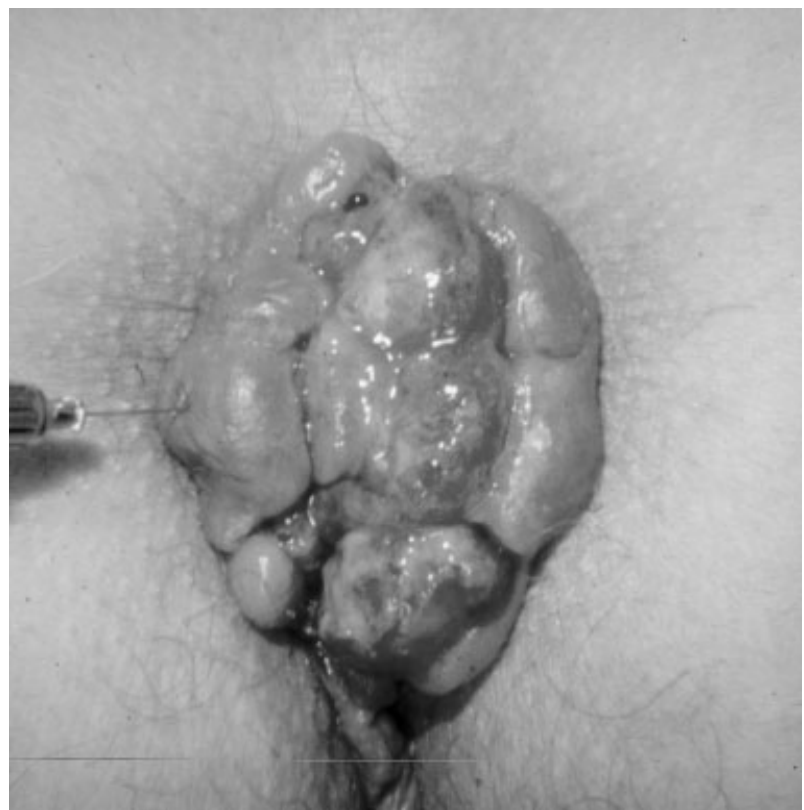

Figure 5 Injection of local anesthetic.

trend to an earlier recovery in the excision and ligation group. $^{37}$

\section{Crohn Disease and Hemorrhoids}

Crohn disease is frequently associated with skin tags that may be confused with hemorrhoids. Crohn skin tags are generally larger and less tender than hemorrhoids. Hemorrhoid disease, however, may occur in conjunction with Crohn disease. Anorectal surgery when Crohn disease is active increases the risks for complications, but can generally be performed when disease is quiescent. ${ }^{38}$

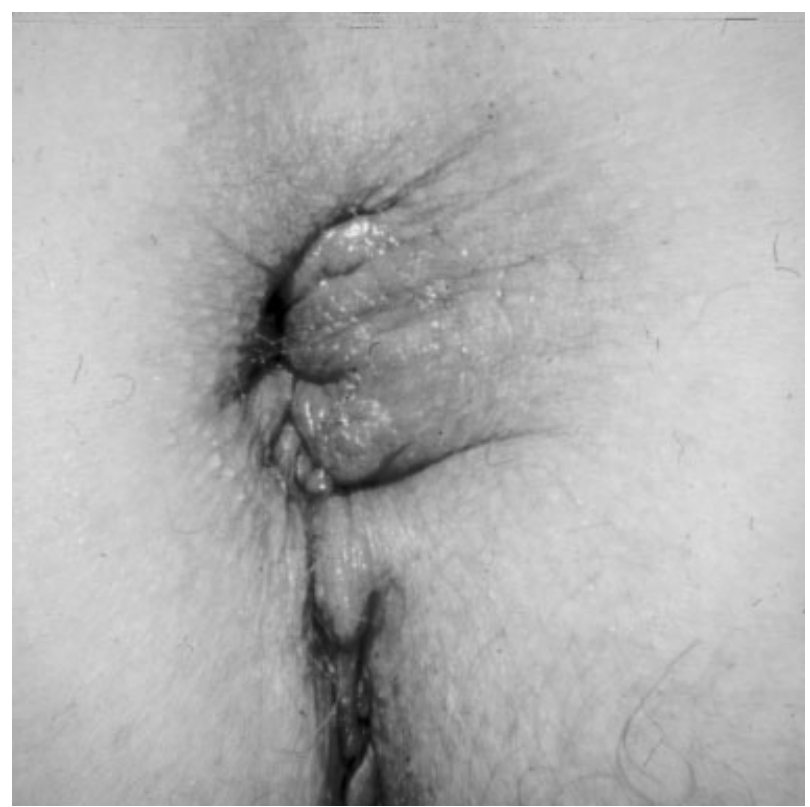

Figure 6 Office treatment of acute hemorrhoid disease. 


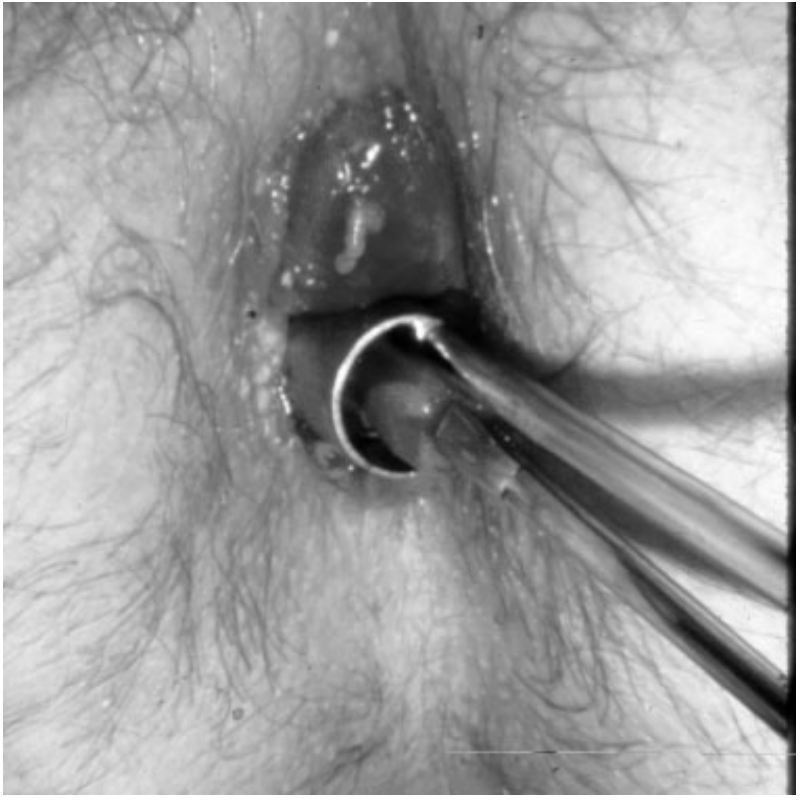

Figure 7 Ligation of reduced internal hemorrhoids without anoscope after local block.

\section{Pregnancy}

Hemorrhoid symptoms are greatest during the third trimester when venous obstruction from the gravid uterus occurs, and dehydration along with constipation are common. The majority of patients can be treated nonoperatively with their symptoms resolving after delivery. ${ }^{39}$ Although a formal hemorrhoidectomy is uncommon, excision of a thrombosis is frequently performed. These procedures can be performed under local anesthesia with very low risk to the mother and fetus. ${ }^{40}$ Thromboses are commonly excised in the office using only a local anesthetic with or without epinephrine. Although examination and excision in the kneechest position can be performed, it may be easier and more physiologic in the left lateral position due to the gravid uterus. Routine postoperative instructions are provided.

\section{Cirrhosis and Portal Hypertension}

The incidence of hemorrhoid disease in those with portal hypertension is no different than the general population. ${ }^{41-43}$ As with other varices in portal hypertension, rectal varices are a result of a portosystemic communication. The superior hemorrhoid veins of the portal circulation decompress by way of the middle and inferior hemorrhoid veins into the iliac veins. Rectal varices are common, but unlike other varices, uncommonly bleed and account for $<1 \%$ of massive bleeding in portal hypertension. ${ }^{44}$ If rectal varices bleed, treatment is based on decompression of the portal system by transhepatic portosystemic shunt. ${ }^{45}$

\section{Immunocompromised Patients}

The immunocompromised, such as human immunodeficiency virus, acquired immune deficiency syndrome (AIDS), and transplant patients are at greater risk of severe infection and poor wound healing. ${ }^{46-48}$ Symptomatic hemorrhoids should be treated with nonoperative measures or less-invasive approaches such as sclerotherapy when indicated. A small series of 22 AIDS patients with grade 2, 3, and 4 disease had no complications after injection. ${ }^{49}$

\section{CONCLUSION}

Hemorrhoid disease is a common, complex, and multifaceted entity. Patients presenting with signs and symptoms of hemorrhoids should be carefully and thoroughly evaluated to exclude other diseases. There are a variety of nonoperative and operative treatments that have their own benefits and drawbacks. Each patient should be treated individually based on the type and degree of their symptoms as well as considering their other medical problems.

\section{REFERENCES}

1. Johanson JF, Sonnenberg A. The prevalence of hemorrhoids and chronic constipation. An epidemiologic study. Gastroenterology 1990;99:1856-1857

2. Cintron J, Abacarian H. Benign anorectal: hemorrhoids. In: Wolff BG, Fleshman JW, eds. The ASCRS of Colon and Rectal Surgery. New York, NY: Springer-Verlag; 2007: 156-177

3. Smith LE. Hemorrhoids. In: Fazio V, ed. Current Therapy in Colon and Rectal Surgery. St. Louis, MO: Mosby; 2004:11-18

4. Kluiber RM, Wolff BG. Evaluation of anemia caused by hemorrhoidal bleeding. Dis Colon Rectum 1994;37(10): 1006-1007

5. Aigner F, Gruber H, Conrad F, et al. Revised morphology and hemodynamics of the anorectal vascular plexus: impact on the course of hemorrhoidal disease. Int J Colorectal Dis 2009;24(1):105-113

6. Greenspon J, Williams SB, Young HA, Orkin BA. Thrombosed external hemorrhoids: outcome after conservative or surgical management. Dis Colon Rectum 2004;47(9): 1493-1498

7. Johanson JF, Rimm A. Optimal nonsurgical treatment of hemorrhoids: a comparative analysis of infrared coagulation, rubber band ligation, and injection sclerotherapy. Am J Gastroenterol 1992;87(11):1600-1606

8. Bat L, Melzer E, Koler M, Dreznick Z, Shemesh E. Complications of rubber band ligation of symptomatic internal hemorrhoids. Dis Colon Rectum 1993;36(3): 287-290

9. Savioz D, Roche B, Glauser T, Dobrinov A, Ludwig C, Marti MC. Rubber band ligation of hemorrhoids: relapse as a function of time. Int J Colorectal Dis 1998;13(4):154-156

10. Bayer I, Myslovaty B, Picovsky BM. Rubber band ligation of hemorrhoids. Convenient and economic treatment. J Clin Gastroenterol 1996;23(1):50-52 
11. Poon GP, Chu KW, Lau WY, et al. Conventional vs. triple rubber band ligation for hemorrhoids. A prospective, randomized trial. Dis Colon Rectum 1986;29(12):836838

12. Lee HH, Spencer RJ, Beart RW Jr. Multiple hemorrhoidal bandings in a single session. Dis Colon Rectum 1994;37(1): 37-41

13. MacRae HM, McLeod RS. Comparison of hemorrhoidal treatment modalities. A meta-analysis. Dis Colon Rectum 1995;38(7):687-694

14. MacRae HM, McLeod RS. Comparison of hemorrhoidal treatments: a meta-analysis. Can J Surg 1997;40(1):14-17

15. Sim AJ, Murie JA, Mackenzie I. Three year follow-up study on the treatment of first and second degree hemorrhoids by sclerosant injection or rubber band ligation. Surg Gynecol Obstet 1983;157(6):534-536

16. Fleshman J, Madoff R. Hemorrhoids. In: Cameron J, ed. Current Surgical Therapy. Philadelphia, PA: Elsevier; 2004: 245-252

17. Pilkington SA, Bateman AC, Wombwell S, Miller R. Anatomical basis for impotence following haemorrhoid sclerotherapy. Ann R Coll Surg Engl 2000;82(5):303-306

18. Barwell J, Watkins RM, Lloyd-Davies E, Wilkins DC. Lifethreatening retroperitoneal sepsis after hemorrhoid injection sclerotherapy: report of a case. Dis Colon Rectum 1999;42(3): 421-423

19. Ratto C, Donisi L, Parello A, Litta F, Doglietto GB. Evaluation of transanal hemorrhoidal dearterialization as a minimally invasive therapeutic approach to hemorrhoids. Dis Colon Rectum 2010;53(5):803-811

20. Faucheron JL, Gangner Y. Doppler-guided hemorrhoidal artery ligation for the treatment of symptomatic hemorrhoids: early and three-year follow-up results in 100 consecutive patients. Dis Colon Rectum 2008;51(6):945949

21. Conaghan P, Farouk R. Doppler-guided hemorrhoid artery ligation reduces the need for conventional hemorrhoid surgery in patients who fail rubber band ligation treatment. Dis Colon Rectum 2009;52(1):127-130

22. Palimento D, Picchio M, Attanasio U, Lombardi A, Bambini C, Renda A. Stapled and open hemorrhoidectomy: randomized controlled trial of early results. World J Surg 2003;27(2): 203-207

23. Nisar PJ, Acheson AG, Neal KR, Scholefield JH. Stapled hemorrhoidopexy compared with conventional hemorrhoidectomy: systematic review of randomized, controlled trials. Dis Colon Rectum 2004;47(11):1837-1845

24. Chung YC, Wu HJ. Clinical experience of sutureless closed hemorrhoidectomy with LigaSure. Dis Colon Rectum 2003; 46(1):87-92

25. Person B, Wexner SD. Novel technology and innovations in colorectal surgery: the circular stapler for treatment of hemorrhoids and fibrin glue for treatment of perianal fistulae. Surg Innov 2004;11(4):241-252

26. Pescatori M. PPH stapled hemorrhoidectomy - a cautionary note. Dis Colon Rectum 2003;46(1):131

27. Pescatori M. Stapled hemorrhoidectomy: a word of caution. Int J Colorectal Dis 2002;17(5):362-363

28. Holzheimer RG. Hemorrhoidectomy: indications and risks. Eur J Med Res 2004;9(1):18-36

29. Chen HH, Wang JY, Changchien CR, et al. Risk factors associated with posthemorrhoidectomy secondary hemorrhage: a single institution prospective study of 4880 consecutive closed hemorrhoidectomies. Dis Colon Rectum 2002;45:1096-1099

30. Bleday R, Pena JP, Rothenberger DA, Goldberg SM, Buls JG. Symptomatic hemorrhoids: current incidence and complications of operative therapy. Dis Colon Rectum 1992;35(5): 477-481

31. You SY, Kim SH, Chung CS, Lee DK. Open vs. closed hemorrhoidectomy. Dis Colon Rectum 2005;48(1):108113

32. Khan S, Pawlak SE, Eggenberger JC, et al. Surgical treatment of hemorrhoids: prospective, randomized trial comparing closed excisional hemorrhoidectomy and the Harmonic Scalpel technique of excisional hemorrhoidectomy. Dis Colon Rectum 2001;44(6):845-849

33. Andrews BT, Layer GT, Jackson BT, Nicholls RJ. Randomized trial comparing diathermy hemorrhoidectomy with the scissor dissection Milligan-Morgan operation. Dis Colon Rectum 1993;36(6):580-583

34. Ibrahim S, Tsang C, Lee YL, Eu KW, Seow-Choen F. Prospective, randomized trial comparing pain and complications between diathermy and scissors for closed hemorrhoidectomy. Dis Colon Rectum 1998;41(11):1418-1420

35. Hoff SD, Bailey HR, Butts DR, et al. Ambulatory surgical hemorrhoidectomy - a solution to postoperative urinary retention? Dis Colon Rectum 1994;37(12):1242-1244

36. Sneider EB, Maykel JA. Diagnosis and management of symptomatic hemorrhoids. Surg Clin North Am 2010;90(1): $17-32$

37. Rasmussen OO, Larsen KG, Naver L, Christiansen J. Emergency haemorrhoidectomy compared with incision and banding for the treatment of acute strangulated haemorrhoids. A prospective randomised study. Eur J Surg 1991;157(10): 613-614

38. Wolkomir AF, Luchtefeld MA. Surgery for symptomatic hemorrhoids and anal fissures in Crohn's disease. Dis Colon Rectum 1993;36(6):545-547

39. Dietrich CS III, Hill CC, Hueman M. Surgical diseases presenting in pregnancy. Surg Clin North Am 2008;88(2): 403-419, vii-viii

40. Saleeby RG Jr, Rosen L, Stasik JJ, Riether RD, Sheets J, Khubchandani IT. Hemorrhoidectomy during pregnancy: risk or relief? Dis Colon Rectum 1991;34(3):260-261

41. Hosking SW, Smart HL, Johnson AG, Triger DR. Anorectal varices, haemorrhoids, and portal hypertension. Lancet 1989;1(8634):349-352

42. Goenka MK, Kochhar R, Nagi B, Mehta SK. Rectosigmoid varices and other mucosal changes in patients with portal hypertension. Am J Gastroenterol 1991;86(9):1185-1189

43. Bernstein WC. What are hemorrhoids and what is their relationship to the portal venous system? Dis Colon Rectum 1983;26(12):829-834

44. Johansen K, Bardin J, Orloff MJ. Massive bleeding from hemorrhoidal varices in portal hypertension. JAMA 1980; 244(18):2084-2085

45. Shibata D, Brophy DP, Gordon FD, Anastopoulos HT, Sentovich SM, Bleday R. Transjugular intrahepatic portosystemic shunt for treatment of bleeding ectopic varices with portal hypertension. Dis Colon Rectum 1999;42(12): 1581-1585

46. Wexner SD, Smithy WB, Milsom JW, Dailey TH. The surgical management of anorectal diseases in AIDS and pre-AIDS patients. Dis Colon Rectum 1986;29(11) 719-723 
47. Safavi A, Gottesman L, Dailey TH. Anorectal surgery in the HIV + patient: update. Dis Colon Rectum 1991;34(4): 299-304

48. Morandi E, Merlini D, Salvaggio A, Foschi D, Trabucchi E. Prospective study of healing time after hemorrhoidectomy: influence of HIV infection, acquired immunodeficiency syndrome, and anal wound infection. Dis Colon Rectum 1999;42(9):1140-1144

49. Scaglia M, Delaini GG, Destefano I, Hultén L. Injection treatment of hemorrhoids in patients with acquired immunodeficiency syndrome. Dis Colon Rectum 2001; 44(3):401-404 